\title{
Bebeklerde (3-6 ay) Periferik Intravenöz Kateterizasyon Uygulaması Sırasında Kullanılan Müzikli Dönencenin Ağrı Algısına Etkisi $\infty$
}

\author{
Nagihan AKAY ${ }^{1}$, Sema KUĞUOĞLU², Behice EKici
}

Öz

Amaç: Bu araştırma, 3-6 ay arası bebeklerde, periferik intravenöz kateterizasyon uygulaması sırasında kullanılan müzikli dönencenin ağrı algısına etkisini belirlemek amacıyla gerçekleştirilmiştir.

Gereç ve Yöntem: Yarı deneysel olarak 3-6 ay arası toplam 112 bebek ile yürütülen çalışma 2.11.2017 ve 31.01.2018 tarihlerinde bir hastanenin çocuk servisinde gerçekleştirilmiştir. Deney grubunda intravenöz kateterizasyon işlemi sırasında müzikli dönence kullanılırken, kontrol grubuna sadece kateterizasyon uygulanmıştır. Bebek Tanıtıcı Bilgi Formu ve Face Legs Activity Cry Consolability (FLACC) Ağrı Ölçeği ile veriler toplanmıştır. Her iki grupta işlem öncesi, işlem sırası ve işlem sonrasında birbirinden bağımsız iki gözlemci eş zamanlı ağrı ölçeğini puanlamıştır.

Bulgular: Araştırma kapsamına alınan bebeklerin \%52.7'si ( $n=59)$ kız, \%47.3'ü ( $n=53)$ erkektir. Bebeklere ilişkin genel özelliklerin (yaş, tartı, boy) deney ve kontrol grupları arasında benzerlik gösterdiği saptanmıştır. İşlem öncesi ( $p: 0.011 ; p<0.05)$, işlem sırası ( $p: 0.001$; $p<0.01)$ ve işlem sonrasında $(p: 0.001 ; p<0.01)$ kontrol grubunun FLACC ağrı puanları, deney grubu FLACC ağrı puanlarına göre istatistiksel olarak anlamlı düzeyde yüksek bulunmuştur.

Sonuç: Periferik intravenöz kateterizasyon uygulaması sırasında ağrı algısının azaltılmasında müzikli dönence etkili bulunmuştur ve güvenle kullanılabilir.

Anahtar kelimeler: Ağrı, bebek, hemşirelik bakımı, periferik intravenöz kateterizasyon

\begin{abstract}
The Effect of Musical Mobile on Pain Perception Used During Peripheral Intravenous Catheterization in Infants (3-6 Months)

Aim: The aim of this study is to investigate the effect of musical mobile on pain perception used during peripheral intravenous catheterization in infants.

Material and Methods: The semi-experimental study, which was conducted with a total of 112 babies between 3-6 months, was carried out on 2.11.2017 and 31.01.2018 in a hospital's pediatric ward. While the musical mobile was used during the intravenous catheterization procedure in the experimental group, only catheterization was applied to the control group. Data were collected with a descriptive information form and Face Legs Activity Cry Consolability (FLACC) Pain Scale. In both groups, two independent observers scored the simultaneous pain scale before, during, and after the procedure.

Results: $52.7 \%(n=59)$ of the babies included in the study were female and $47.3 \%(n=53)$ were male. It was determined that the general characteristics (age, weight, height) of the babies were similar between experimental and control groups. The FLACC pain scores of the control group before ( $p: 0.011 ; p<0.05)$, during ( $p$ : $0.001 ; p<0.01)$ and after the procedure ( $p: 0.001 ; p<0.01)$ were found to be statistically significantly higher than the experimental group.

Conclusion: Musical mobile has been found effective in reducing pain perception during peripheral intravenous catheterization and can be used safely.

Keywords: Infant, nursing care, pain, peripheral intravenous catheterization
\end{abstract}

${ }^{1}$ Uzman Hemşire, Sancaktepe Şehit Prof. Dr. İlhan Varank Eğitim ve Araştırma Hastanesi, Çocuk Hastalıkları Kliniği, İstanbul/TÜRKiYE,

nagihan.oruc.akay@gmail.com, 053010963 24, ORCID ID: 0000-0001-9935-8640

${ }^{2}$ Prof. Dr, Medipol Üniversitesi, Sağlık Bilimleri Fakültesi, Hemşirelik Bölümü, İstanbul/TÜRKiYE, skuguoglu@medipol.edu.tr, 0506 284 12 19, ORCID ID: 0000-00022794-1068

${ }^{3}$ Dr Öğr. Üyesi, Maltepe Üniversitesi Hemşirelik Yüksekokulu, İstanbul/TÜRKiYE, behiceekici@maltepe.edu.tr, 053041921 37, ORCID ID: 0000-0002-2851-2345

* Çalışma T.C. Maltepe Üniversitesi Sağlık Bilimleri Enstitüsü 2018 Yüksek Lisans Tezi olarak sunulmuştur.

Geliş Tarihi: 27 Nisan 2019, Kabul Tarihi: 02 Kasım 2020

Atıf/Citation: Akay N, Kuğuoğlu S, Ekici B. Bebeklerde (3-6 ay) Periferik İntravenöz Kateterizasyon Uygulaması Sırasında Kullanılan Müzikli Dönencenin Ağrı Algısına Etkisi. Hacettepe Üniversitesi Hemşirelik Fakültesi Dergisi 2021;8(1):16-21. DOI: 10.31125/hunhemsire.906918 


\section{GíRiş}

Uluslararası Ağrı Araştırmaları Derneği ağrıyı "vücudun herhangi bir yerinden kaynaklanan, gerçek ya da olası bir doku hasarı ile birlikte bulunan, hastanın geçmişteki deneyimleri ile ilgili, duyusal, afektif, hoş olmayan bir duygu" olarak tanımlamaktadır ${ }^{1,2}$. Yapılan birçok çalışma, ağrının intrauterin dönemden itibaren hissedildiğini kanıtlamakta, bebeklik dönemlerinde yaşanılan ağrının olumsuz ve kalıcı iz bırakabildiğini göstermektedir ${ }^{2-7}$.

Gelişimsel dönemlere göre ağrı ile ilgili algılamalar değişmektedir. Örneğin, 0-3 ay arasındaki bebekler ağrıya refleksleri ile tepki verirken, 3-6 ay arasındaki bebeklerde öfke ve üzüntü tepkileri eklenmektedir. 6-18 ay arasında bebeklerde ise ağrılı uyarana karşı korku gelişir ve ağrıyı lokalize edebilirler ${ }^{3,4}$.

Ağrının giderilmesinde etkili olan nonfarmakolojik yöntemler tek başına veya farmakolojik yöntemler ile birlikte kullanılabilmektedir8,9. Dikkati başka yöne çekme, çocuğun odağını ilgi çekici bir uyarıcı ile ağrılı uyarandan uzaklaştırmaya yarayan bilişsel ve davranışsal bir ilaç dışı yöntemdir. Bu yöntem ağrıyı ortadan kaldırmaz, fakat ağrıya katılma kapasitesini engellemeye ve ağrıyı daha tolere edilebilir hale getirmeye yardımcı olmaktadır ${ }^{10,11}$. Dikkati başka yöne çekmenin, ağrı hissini azaltan sistemleri tetikleyerek ağrılı uyarana verilen yanıtları değiştirdiği de öne sürülmektedir. Genel olarak dikkati başka yöne çekme yöntemlerinin etkinliğinin kapı kontrol teorisine dayandığı kabul görmektedir ${ }^{8}$.

Dikkati başka yöne çekmenin aktif ve pasif olmak üzere iki türü vardır. Aktif yöntemlerde ağrıya sebep olan girişimler sırasında çocukların bir eylemde bulunmaları teşvik edilir. Pasif dikkati başka yöne çekme yöntemleri ise çocuğun açık katılımından ziyade bir etkinliği veya uyaranı gözlemlemesi ile sağlanır. İşitsel ve görsel teknikler pasif yöntemlerin en yaygın kullanılan türleridir ${ }^{12,13}$.

İnvaziv girişimlere bağı ı akut ağrıda kullanılabilecek en etkili nonfarmakolojik yöntem dikkati başka yöne çekmedir. Dikkati başka yöne çekme yöntemi ile yapılan benzer çalışmalar, ağrı kontrolünde bu yöntemin etkinliğini göstermektedir ${ }^{14-16,25}$. Çocuklarda ağrı yönetim stratejilerini geliştirmek, çocuklara özgü ihtiyaçları dikkate alarak optimal ağrı yönetimi uygulamalarını aydınlatmak için daha fazla çalışmaya gereksinim vardır ${ }^{7,12}$. Pediatri hemşireliğinin bakım ilkelerinden biri de atravmatik bakım felsefesidir. Atravmatik bakım uygulamaları kapsamında ağrı yönetimi önemli bir yer tutmaktadır. Bu çalışma ile ekonomik, kullanımı kolay bir araç ile dikkati başka yöne çekmenin ağı algısına etkisinin belirlenmesi hedeflenmiştir.

\section{Araştırmanın Amacı}

$\mathrm{Bu}$ araştırma; periferik intravenöz kateterizasyon uygulaması sırasında bebeklerin hissettiği ağrı algısına, müzikli dönencenin etkisini saptamak amacıyla gerçekleştirilmiştir.

\section{GEREÇ ve YÖNTEM}

\section{Araştırmanın Türü}

$\mathrm{Bu}$ araştırma; periferik intravenöz kateterizasyon uygulaması sırasında bebeklerin hissettiği ağrı algısına, müzikli dönencenin etkisini saptamak amacıyla yarı deneysel tasarımda gerçekleştirilmiştir.

\section{Araştırma Evren ve Örneklemi}

Yarı deneysel nitelikte tasarlanan bu araştırma istanbul Anadolu Yakası'nda bulunan bir eğitim ve araştırma hastanesinin çocuk servisinde 2.11.2017 ve 31.01.2018 tarihleri arasında gerçekleştirilmiştir. Araştırma evrenini hastaneye başvuran 3-6 aylık bebekler oluşturmuştur. Yapılan güç analizi sonucunda, \%80 güç ve $\% 95$ güven aralığı ile örneklem büyüklüğünün her grup için 52 olmak üzere toplam minimum 104 olması gerektiği belirlenmiştir. Araştırmanın yürütüldüğü sürede 11 aile araştırmaya katılmayı kabul etmediği, 20 bebek örneklem seçim kriterlerine uymadığı, 8 aile yabancı uyruklu olduğu için dil problemi nedeniyle iletişim kurulamadığından araştırmaya dahil edilmemiştir. Araştırma 56 deney, 56 kontrol grubu olmak üzere toplam 112 bebek ile yürütülmüştür.

Bebeklerin gruplara randomize atanması için takvimin tek sayı günleri getirilen bebekler deney grubunu, çift sayı günleri getirilen bebekler kontrol grubunu oluşturmuştur. Konjenital veya kronik bir sağlık sorunu olmayan, son 4 saat içerisinde analjezik etkili bir ilaç almamış olan, evinde müzikli dönencesi bulunmayan ve araştırmaya katılmayı kabul eden ailelerin bebekleri çalışmaya dahil edilmiştir. Hastaneye yatışının ilk günü olan ve bu yatışta ilk kez kateter takılacak olan bebekler çalışmaya alınmıştır.

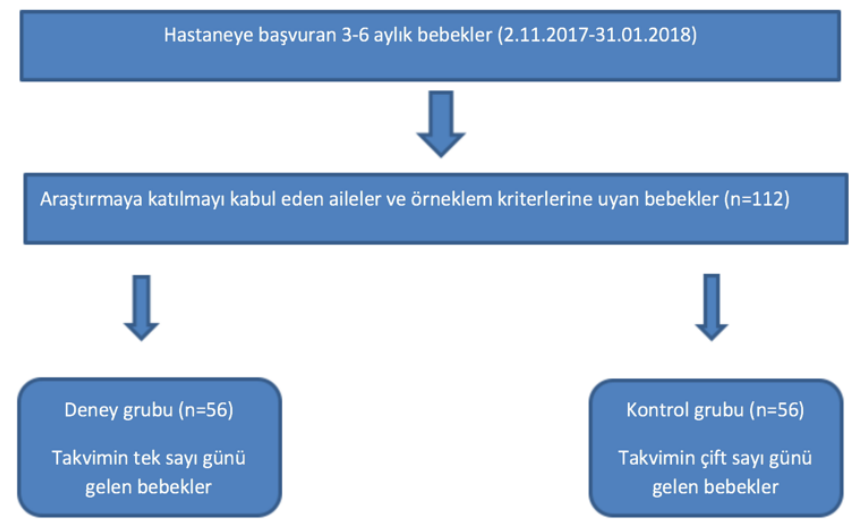

\section{Veri Toplama Araçları}

Araştırmada veriler; Bebek Tanıtıc Bilgi Formu ve (Face, Legs, Activity, Cry, Consolability) -FLACC (Yüz ifadesi, Bacak hareketleri, Aktivite, Ağlama, Teselli edilebilirlik- YBAAT) Ağrı Ölçeği kullanılarak toplanmıştır. Araştırmacılar tarafından hazırlanan bebek tanıtıcı bilgi formu, bebeğe ilişkin cinsiyet, yaş, ağılık, boy, daha önceki invaziv girişim sayısı, bebeğe primer bakım veren kişinin yakınlık derecesi ve hastanede yatma deneyimi olup olmadığına dair bilgileri içeren toplam yedi sorudan oluşmaktadır.

Araştırmada deney ve kontrol gruplarındaki bebeklerin işlem öncesi, sırası ve sonrasındaki ilk dakika içerisinde ağrı puanlarının hesaplanmasında FLACC Ağrı Ölçeği kullanılmıştır. Ölçek Merkel ve arkadaşları tarafından 1997 yılında geliştirilmiş olup, 2 ay ve 7 yaş arası çocuklarda prosedurel ve postoperatif ağrıların değerlendirilmesinde kullanılan gözlemsel bir davranış ölçeğidir ${ }^{19}$. Türkçeye 
uyarlaması 2005 yılında Şenaylı ve arkadaşları tarafından YBAAT ağrı skalası olarak yapıımıştır. Çalışmada 1 ay ile 9 yaş arasındaki çocukların postoperatif ağrı değerlendirmeleri yapılmış ve çalışma sonuçları skalanın Türkçe geçerlilikgüvenirliğini göstermiştir ${ }^{20}$. Yüz ifadesi, bacak hareketleri, aktivite, ağlama ve teselli edilebilirlik olarak beş kategoride değerlendirme yapılarak FLACC ağrı ölçek puanı elde edilmektedir. Her bir kategori için 0, 1, ya da 2 puan verilerek, 0- 10 arası toplam puana ulaşılmaktadır. Ağrı şiddeti arttıkça toplam puan yükselmekte, ağrı şiddeti azaldıkça toplam puan düşmektedir ${ }^{19,20}$.

\section{Veri Toplama Araçlarının Uygulanması}

Çalışmanın yürütüldüğü çocuk servisi müdahale odasında müdahale sırasında dış faktörleri engellemek amacıyla başka bir işlem uygulanmamış olup, işlem sırasında müdahale odasına bebek ve ebeveyni, ağrı ölçeğini puanlayan araştırmacı hemşire, kateteri uygulayan hemşire ile ağrı ölçeğini puanlayan ikinci hemşire dışında kimse alınmamıştır.

Araştırmada kullanılan müzikli dönence bebeğin baş tarafına göre, ayaklı bir askılığa sedye seviyesinden $25-30 \mathrm{~cm}$ yukarıda olacak şekilde sabitlenmiştir. Çalıştırıldığında müzik çalarak dönmeye başlayan 3 adet peluş oyuncağı ve 3 adet yıldız figürü vardır.

Bebek Tanıtıcı Bilgi Formu araştırmacı tarafından doldurulmuş, bebeklerin boy ve tartı ölçümleri araştırmacı tarafından kalibrasyonları yapılmış araçlar ile yapılmıştır. Araştırma boyunca aynı cihazlar kullanılmıştır. Kataterizasyon her iki gruba da aynı deneyimli hemşire tarafından uygulanmıştır. Kateterizasyon işlemi için sağ veya sol el metakarpal venler kullanılmış olup, 24 Gauge (sarı renk) intravenöz kanül ile işlem gerçekleştirilmiştir. Damar yolu ilk seferde açılamayan bebek olmamıştır.

Her iki grupta işlem öncesi, işlem sırası ve işlem sonrasında araştırmacı ve ağrı ölçeği konusunda eğitim almış hemşire birbirinden bağımsız olarak eş zamanlı ağrı ölçeğini puanlamıştır. İşlemler toplam ortalama 10 dakika sürmüştür.

Boy ve ağılık ölçümleri yapılan bebek sedyeye alınıp işlem öncesi ağrı puanı ölçülmüştür. Kontrol grubundaki bebeklere rutin kateterizasyon işlemi yapılmış olup, deney grubundakilere ise müzikli dönence çalıştırıldıktan sonra kateter uygulaması yapılmıştır. Her iki grupta da işlem sırasında bebeğin dikkatini çekecek bir uygulama (el çırpma, emzik verme) yapılmamıştır.

\section{Verilerin Analizi}

Çalışmada elde edilen bulgular değerlendirilirken, istatistiksel analizler için IBM SPSS Statistics 22 (IBM SPSS, Türkiye) programı kullanılmıştır. Değişkenlerin normal dağılıma uygunluğu Shapiro Wilks testi ile değerlendirilmiştir. Verilerin değerlendirilmesinde tanımlayıcı istatistiksel metotlar ve (ortalama, standart sapma, frekans) niteliksel verilerin iki grup arası değerlendirmelerinde Mann Whitney U Testi kullanılmıştır. İşlem öncesi, sırası ve sonrası niceliksel verilerin değerlendirilmesinde Friedman Testi, gözlemciler arası uyumun değerlendirilmesinde Sınıf İçi Korelasyon Katsayısı kullanılmıştır. Veriler arasındaki ilişkinin değerlendirilmesinde Spearman Rho Korelasyon Analizi ve niteliksel verilerin değerlendirilmesinde Continuity (Yates) Düzeltmeli Ki-Kare Testi kullanılmıştır.

\section{Araştırmanın Etik Boyutu}

Araştırmaya başlamadan önce T.C. Maltepe Üniversitesi Etik Kurulu'ndan ve İstanbul Fatih Sultan Mehmet Eğitim ve Araştırma Hastanesi Bilimsel Çalışmalar Komisyonu'ndan 18.10.2017 tarih ve 617 sayı numarası ile etik kurul onayı alınmıştır. Araştırmaya katılmaya gönüllü olan ebeveynlere araştırmanın amacı, planı ve süresi hakkında bilgilendirme yapılmış; bilgilendirilmiş hasta onam formu ile yasal temsilcilerin yazılı onamları alınmıştır. Ayrıca çalışmanın yürütüleceği çocuk servisi çalışanları araştırma hakkında bilgilendirilmiştir.

\section{Araştırmanın Sınırlılıkları}

Araştırma belirli tarihlerde eğitim ve araştırma hastanesine başvuran, örneklem kriterlerine uyan ve çalışmayı kabul eden ailelerin bebekleri ile yürütülmüştür. Bu nedenle araştırma sonuçları bu gruba genellenebilir.

\section{BULGULAR}

Araştırmaya katılan bebeklerin \%52.7'si ( $n=59)$ kız, \%47.3'ü $(n=53)$ erkektir. Bebeklerin \%50'si $(n=56)$ deney, \%50'si $(n=56)$ kontrol grubuna alınmıştır. Deney grubunun yaş (ay) ortalaması $3.98 \pm 0.94$ ay, kontrol grubunun yaş (ay) ortalaması $4.07 \pm 1,02^{\prime}$ aydır. Bebeklerin ağırlıklarının ortalamaları deney grubunda $6.88 \pm 0.88$, kontrol grubunda $6.7 \pm 0.69$, boy ortalamaları ise deney grubunda $63.80 \pm 4.42$, kontrol grubunda $62.48 \pm 4.20 \mathrm{~cm}$ 'dir.

Bebeklere daha önce hastane yatışlarında uygulanan invaziv girişim sayıları ortalamaları deney grubunda 8.91 \pm 1.10 , kontrol grubunda $8.77 \pm 1.16$ 'dır.

Deney ve kontrol grubundaki bebeklerin tümüne (\%100.0) anneleri bakım vermektedir. Deney grubundaki bebeklerin $\% 10.7$ 'sinin, kontrol grubundaki bebeklerin \%14.3'ünün daha önceden hastanede yatma deneyimi olduğu saptanmıştır (Tablo 1).

Tablo 1. Bebeklere İlişkin Genel Özellikler

\begin{tabular}{|c|c|c|c|c|c|c|}
\hline \multirow{2}{*}{$\begin{array}{l}\text { Genel } \\
\text { Özellikler }\end{array}$} & $\begin{array}{l}\text { Deney } \\
(n=56)\end{array}$ & \multicolumn{2}{|c|}{$\begin{array}{l}\text { Kontrol } \\
(n=56)\end{array}$} & $\begin{array}{c}\text { Total } \\
(n=112)\end{array}$ & z & p \\
\hline & Ort $\pm S S$ & \multicolumn{2}{|c|}{ Ort $\pm S S$} & Ort $\pm S S$ & & \\
\hline Yaş (ay) & $3.98 \pm 0.94$ & \multicolumn{2}{|c|}{$4.07 \pm 1,02$} & $4.03 \pm 0.98$ & $\begin{array}{c}- \\
0.415\end{array}$ & 0.678 \\
\hline Kilo (kg) & $6.88 \pm 0.88$ & \multicolumn{2}{|c|}{$6.77 \pm 0.69$} & $6.83 \pm 0.79$ & $\begin{array}{c}- \\
0.854 \\
\end{array}$ & 0.393 \\
\hline Boy (cm) & $63.80 \pm 4.42$ & \multicolumn{2}{|c|}{$62.48 \pm 4.20$} & $63.14 \pm 4.34$ & $\begin{array}{c}- \\
1.630 \\
\end{array}$ & 0.103 \\
\hline \multirow[t]{2}{*}{$\begin{array}{l}\text { IV girişim } \\
\text { sayısı }(n)\end{array}$} & $8.91 \pm 1.10$ & \multicolumn{2}{|c|}{$8.77 \pm 1.16$} & $8.84 \pm 1.13$ & $\begin{array}{l}- \\
1.175 \\
\end{array}$ & 0.240 \\
\hline & n (\%) & \multicolumn{2}{|c|}{$n(\%)$} & $n(\%)$ & $\chi^{2}$ & p \\
\hline \multirow{2}{*}{ Cinsiyet } & Kız & $\begin{array}{c}27 \\
(\% 48.2) \\
\end{array}$ & $\begin{array}{c}32 \\
(\% 57.1) \\
\end{array}$ & $59(\% 52.7)$ & \multirow{2}{*}{0.573} & \multirow{2}{*}{0.449} \\
\hline & Erkek & $\begin{array}{c}29 \\
(\% 51.8)\end{array}$ & $\begin{array}{c}24 \\
(\% 42.9)\end{array}$ & $53(\% 47.3)$ & & \\
\hline \multirow{2}{*}{$\begin{array}{l}\text { Hastanede } \\
\text { yatma } \\
\text { deneyimi }\end{array}$} & Yok & $\begin{array}{c}50 \\
(\% 89.3) \\
\end{array}$ & $\begin{array}{c}48 \\
(\% 85.7) \\
\end{array}$ & $98(\% 87.5)$ & \multirow{2}{*}{0,082} & \multirow{2}{*}{0,775} \\
\hline & Var & $\begin{array}{c}6 \\
(\% 10.7)\end{array}$ & $\begin{array}{c}8 \\
(\% 14.3)\end{array}$ & $14(\% 12.5)$ & & \\
\hline
\end{tabular}

Z: Mann Whitney U Testi, $\chi^{2}$ : Continuity(Yates) Düzeltmeli Ki-Kare Testi 
Deney ve kontrol grubundaki bebeklerin yaşları, kiloları, boyları, cinsiyetleri, hastanede yatma deneyimleri ve daha önce uygulanan invaziv girişim sayıları açısından gruplar arasında istatistiksel olarak anlamlı bir farklılık saptanmamıştır ( $p>0.05$ ) (Tablo 1 ).

Gözlemcilerin işlem öncesi, sırası ve sonrası FLACC Ağrı Ölçeği ölçümleri arasında sırasıyla \%99.2, \%99.8 ve \%99.9 düzeylerinde ve istatistiksel olarak anlamlı uyum saptanmıştır. $\left(p_{1}: 0.001, p_{2}: 0.001, p_{3}: 0.001 ; p<0.01\right)$ (Tablo 2).

Tablo 2. İşlem Öncesi, işlem Sırası ve İşlem Sonrası FLACC Ağrı Ölçeği'nin Gözlemciler Arası Uyum Değerlendirmesi

\begin{tabular}{|l|c|c|c|c|}
\hline \multirow{2}{*}{$\begin{array}{l}\text { FLACC Ağrı } \\
\text { Ölıceği }\end{array}$} & \multirow{2}{*}{ ICC } & \multicolumn{2}{|c|}{ \%95 GA } & \multirow{2}{*}{$p$} \\
\cline { 3 - 4 } & & Alt Sınır & $\begin{array}{c}\text { Üst } \\
\text { Sınır }\end{array}$ & \\
\hline Iş̧lem öncesi & 0.992 & 0.977 & 0.989 & $\mathbf{0 . 0 0 1 * *}$ \\
\hline Iş̧lem sırası & 0.998 & 0.997 & 0.999 & $\mathbf{0 . 0 0 1 * *}$ \\
\hline Iş̧lem sonrası & 0.999 & 0.998 & 0.999 & $\mathbf{0 . 0 0 1 * *}$ \\
\hline
\end{tabular}

İşlem öncesi ağrı puanlarına bakıldığında deney grubu ortalaması $0.18 \pm 0.43$, kontrol grubu ortalaması $0.43 \pm 0.60$ 'dır. İşlem sırasında ağrı puanları deney grubunda ortalama 2.71 \pm 1.49 , kontrol grubunda ortalama $8.63 \pm 1.50$ 'dir. İşlem sonrası ağrı puanları deney grubunda ortalama $0.59 \pm 0.71$, kontrol grubunda ortalama $6.29 \pm 1.72$ 'dir. İşlem öncesinde, sırasında ve sonrasında kontrol grubunun FLACC ağrı skorlarının ortalaması, deney grubundan istatistiksel olarak anlamlı düzeyde yüksek olarak saptanmıştır $(\mathrm{p}<0.01)$ (Tablo 3 ).

Tablo 3. İșlem Öncesi, Sırası ve Sonrası Grup içi ve Gruplar Arası FLACC Ağrı Ölçeği'nin Değerlendirilmesi

\begin{tabular}{|c|c|c|c|c|c|}
\hline \multirow{2}{*}{$\begin{array}{l}\text { FLACC } \\
\text { Ağrı } \\
\text { Ölçeği }\end{array}$} & $\begin{array}{l}\text { Deney } \\
(n=56)\end{array}$ & $\begin{array}{l}\text { Kontrol } \\
(n=56)\end{array}$ & $\begin{array}{c}\text { Total } \\
(n=112)\end{array}$ & \multirow[t]{2}{*}{ Z } & \multirow[t]{2}{*}{ p } \\
\hline & Ort $\pm S S$ & Ort $\pm S S$ & Ort $\pm S S$ & & \\
\hline $\begin{array}{l}\text { İşlem } \\
\text { öncesi }\end{array}$ & $\begin{array}{c}0.18 \pm 0.4 \\
3\end{array}$ & $\begin{array}{c}0.43 \pm 0.6 \\
0\end{array}$ & $\begin{array}{c}0.30 \pm 0.5 \\
3\end{array}$ & $\begin{array}{c}- \\
2.55 \\
7\end{array}$ & $0.011^{*}$ \\
\hline $\begin{array}{l}\text { İşlem } \\
\text { sırası }\end{array}$ & $\begin{array}{c}2.71 \pm 1.4 \\
9\end{array}$ & $\begin{array}{c}8.63 \pm 1.5 \\
0\end{array}$ & $\begin{array}{c}5.67 \pm 3.3 \\
2\end{array}$ & $\begin{array}{c}- \\
8.93 \\
0\end{array}$ & $\begin{array}{c}0.001 * \\
*\end{array}$ \\
\hline $\begin{array}{l}\text { Işlem } \\
\text { sonras } \\
1\end{array}$ & $\begin{array}{c}0.59 \pm 0.7 \\
1\end{array}$ & $\begin{array}{c}6.29 \pm 1.7 \\
2\end{array}$ & $\begin{array}{c}3.44 \pm 3.1 \\
5\end{array}$ & $\begin{array}{c}- \\
9.15 \\
4\end{array}$ & $\begin{array}{c}0.001 * \\
*\end{array}$ \\
\hline$\chi^{2}$ & 103.242 & 110.507 & & & \\
\hline$p$ & $0.001 * *$ & $0.001 * *$ & & & \\
\hline
\end{tabular}

Z: Mann Whitney U Testi, $\chi^{2}$ : Friedman Testi, ${ }^{*} p<0.05,{ }^{* *} p<0.01$

Tabloda belirtilmemekle birlikte yaş, tartı, boy ve cinsiyete göre deney ve kontrol grubunda işlem öncesi, işlem sırası ve işlem sonrası FLACC ağrı skorları arasında istatistiksel olarak anlamlı bir farklılık saptanmamıştır $(p>0.05)$. Kontrol grubundaki bebeklerden hastanede yatma deneyimi olanların işlem öncesi FLACC ağrı skorları ortalamasının, hastanede yatma deneyimi olmayan bebeklerin ağrı skoru ortalamalarından anlamlı düzeyde yüksek olduğu belirlenmiştir ( $\mathrm{p}: 0.008 ; \mathrm{p}<0.01)$ (Tablo 4). Deney grubunda bebeklere uygulanan invaziv girişim sayısı ile FLACC ağrı skorları arasında \%29.9 düzeyinde (r:0.299, p:0.025; $\mathrm{p}<0.05)$, kontrol grubunda bebeklere uygulanan invaziv girişim sayısı ile FLACC ağrı skorları arasında \%30.3 düzeyinde anlamlı bir artış saptanmıştır (Tablo 5).

Tablo 4. İnvaziv Girişim Sayısına Göre İşlem Öncesi, İşlem Sırası ve İşlem Sonrası Grup i̇çi ve Gruplar Arası FLACC Ağrı Ölçeği' nin Değerlendirilmesi

\begin{tabular}{|l|l|l|l|}
\hline \multirow{2}{*}{ FLACC Ağrı Ölçeği } & \multicolumn{2}{l|}{ IV girişim sayısı (n) } \\
\cline { 3 - 4 } & $\mathbf{r}$ & $\mathbf{P}$ \\
\hline \multirow{4}{*}{ Deney } & Işlem öncesi & $\mathbf{0 . 2 9 9}$ & $\mathbf{0 . 0 2 5 *}$ \\
\cline { 2 - 4 } & İ̧̧lem sırası & 0.252 & 0.061 \\
\cline { 2 - 4 } & İşlem sonrası & 0.205 & 0.130 \\
\hline \multirow{3}{*}{ Kontrol } & İ̧̧lem öncesi & $\mathbf{0 , 3 0 3}$ & $\mathbf{0 . 0 2 3 *}$ \\
\cline { 2 - 4 } & İşlem sırası & 0.037 & 0.785 \\
\cline { 2 - 4 } & işlem sonrası & 0.030 & 0.827 \\
\hline
\end{tabular}

r: Spearman Rho Korelasyon Analizi, * $\mathrm{p}<0.05$

Tablo 5. İnvaziv Girişim Sayısına Göre İşlem Öncesi, İşlem Sırası ve İşlem Sonrası Grup İçi ve Gruplar Arası FLACC Ağrı Ölçeği' nin Değerlendirilmesi

\begin{tabular}{|c|c|c|c|c|c|}
\hline \multirow{3}{*}{\multicolumn{2}{|c|}{ FLACC Ağrı Ölçeği }} & \multicolumn{2}{|c|}{$\begin{array}{ll}\text { Hastanede } & \text { Yatma } \\
\text { Deneyimi } & \\
\end{array}$} & \multirow{3}{*}{$\mathbf{Z}$} & \multirow{3}{*}{$\mathbf{P}$} \\
\hline & & Yok & Var & & \\
\hline & & Ort $\pm S S$ & Ort $\pm S S$ & & \\
\hline \multirow{5}{*}{ Deney } & $\begin{array}{l}\text { İşlem } \\
\text { öncesi }\end{array}$ & $0.10 \pm 0.30$ & $0.83 \pm 0.75$ & -3.638 & $0.001 * *$ \\
\hline & $\begin{array}{l}\text { İşlem } \\
\text { sırası }\end{array}$ & $2.54 \pm 1.34$ & $4.17 \pm 1.94$ & -2.112 & $0.035^{*}$ \\
\hline & $\begin{array}{l}\text { İşlem } \\
\text { sonrası }\end{array}$ & $0.50 \pm 0.65$ & $1.33 \pm 0.82$ & -2.532 & $0.011^{*}$ \\
\hline & $\chi^{2}$ & 93,281 & 10,174 & & \\
\hline & $p$ & $0,001^{* *}$ & $0,006^{* *}$ & & \\
\hline \multirow{5}{*}{ Kontrol } & $\begin{array}{l}\text { İşlem } \\
\text { öncesi }\end{array}$ & $0.33 \pm 0.52$ & $1.00 \pm 0.76$ & -2.644 & $0.008^{* *}$ \\
\hline & $\begin{array}{l}\text { İşlem } \\
\text { sırası }\end{array}$ & $8.67 \pm 1.21$ & $8.38 \pm 2.77$ & -0.881 & 0.378 \\
\hline & $\begin{array}{l}\text { İşlem } \\
\text { sonrası }\end{array}$ & $6.25 \pm 1.58$ & $6.50 \pm 2.56$ & -1.001 & 0.317 \\
\hline & $\chi^{2}$ & 95.032 & 15.548 & & \\
\hline & $p$ & $0.001^{* *}$ & $0.001^{* *}$ & & \\
\hline
\end{tabular}

Z: Mann Whitney U Testi , $\chi^{2}$ : Friedman Testi, ${ }^{*} p<0.05,{ }^{* *} p<0.01$

\section{TARTIŞMA}

3-6 ay arası bebeklerde periferik intravenöz kateterizasyon uygulaması sırasında kullanılan müzikli dönencenin ağrı algısına etkisini belirlemek amacıyla yürütülen yarı deneysel bu çalışmada, deney ve kontrol grubundaki bebeklerin ağrı algısını etkileyebilecek özellikler açısından benzer oldukları belirlenmiştir. $\mathrm{Bu}$ benzerlik, her iki grubun homojen dağıldığını, ağrı algısını etkileyebilecek kontrol değişkenlerinin çalışma bulgularına etkisinin olmadığını kanıtlamaktadır.

Literatürde ${ }^{2,4,11}$ ağrının yaş, cinsiyet, kültür gibi değişkenlerden etkilendiği ancak, bu değişkenlerin ağrıya etkisinin bireyler arasında farklılıklar gösterdiği savunulmaktadır. Çalışmamızda ağrı algısı ve yaş faktörü arasında anlamlı bir ilişki bulunmamıştır. Bu açıdan bulgular benzer çalışma sonuçları ile benzerlik göstermektedir ${ }^{21,22}$. Farklı kaynaklar yaş arttıkça başa çıkma yöntemlerinin gelişmesiyle ağrı algısının azaldığını savunmaktadır $3,23,24$.

Araştırmamızda bebeklerin yaş aralığının 3-6 ay ile sınırlandırılmış olması nedeni ile yaş, tartı ve boy değişkenlerinin ağrı algısını etkilemediği düşünülmüştür. Çalışmamızda deney ve kontrol gruplarında cinsiyete göre ağrı puanları arasında işlem öncesi, sırası ve sonrasında 
istatistiksel olarak anlamlı bir farklılık saptanmamıştır ( $p>$ 0.01). Yapılan birçok çalışma cinsiyetin ağrı algısı üzerinde anlamlı bir etkisi olmadığını savunurken ${ }^{22,24-26}$, Tüfekci ve Erci'nin ${ }^{24}$ çalışmasında kız çocuklarının ağrı puan ortalaması, erkek çocuklara göre daha yüksek bulunmuş, ancak istatistiksel olarak anlamlı kabul edilmemiştir.

Araştırmada deney ve kontrol grubunda yer alan tüm bebeklere $(n=112)$ bakım veren primer kişi anne olarak tespit edilmiştir. Bu nedenle ağrılı işlem sırasında annenin varlığının ağrı algısına etkisi tartışılamamıştır. Özdemir ve Tüfekci'nin ${ }^{25}$ çalışmasında her iki grupta da yanında annesi bulunan bebeklerin ağrı puanının, diğer kişilerin bulunduğu bebeklere göre anlamlı olarak daha düşük olduğu bulunmuştur.

Daha önceki invaziv girişim sayısına bakıldığında; deney grubunda bebeklere uygulanan invaziv girişim sayısı ile FLACC ağrı skorları arasında pozitif yönde, istatistiksel olarak anlamlı ilişki saptanmıştır ( $r: 0.299, p: 0.025 ; p<0.05)$. Kontrol grubunda bebeklere uygulanan invaziv girişim sayısı ile FLACC ağrı skorları arasında pozitif yönde, istatistiksel olarak anlamlı ilişki bulunmuştur. (r:0.303, p:0.23; p<0.05). Bu bulgu ağrılı işlemlere maruz kalma durumunun ağrı eşiği üzerindeki olumsuz etkisini gösteren literatür ile uyumludur 2,22,24.

Hastanede yatma deneyimi olan kontrol grubundaki bebeklerin işlem öncesi FLACC ağrı skorları, hastanede yatma deneyimi olmayan bebeklerden istatistiksel olarak anlamlı düzeyde yüksek saptanmıştır ( $p: 0.008 ; p<0.01$ ). Hastanede yatma deneyimi olan deney grubundaki bebeklerin işlem öncesi ( $p: 0.001)$, işlem sırası ( $p: 0.035)$ ve işlem sonrası ( $p: 0.011)$ FLACC ağrı skorları, hastanede yatma deneyimi olmayan bebeklerden istatistiksel olarak anlamlı düzeyde yüksek saptanmıştır $(p<0.01)$. Bisogni ve arkadaşlarının ${ }^{27}$ yaptığı çalışmada, kronik hastalık nedeniyle hastanede yatan çocukların kan alma işlemlerinde daha düşük ağrı eşiğine sahip olduğu bulunmuştur.

Başbakkal ve arkadaşlarının ${ }^{28}$ 3-6 yaş grubu çocuğun akut hastalık nedeniyle hastaneye yatmasını incelemiş, hastaneye yatış öncesi ve taburculuk sonrası davranışlarda farklılık ile ilgili istatistiksel anlamlı sonuçlara ulaşmıştır. Tuna ve Açıkgöz'ün ${ }^{22}$ çalışmasında hastanede yatma deneyimi olan çocuklarda ağrı puanının diğer çocuklara göre anlamlı olarak yüksek olduğunu saptamıştır. Bu bulgular çocuklarda ağrının duygusal bilgi olarak depolanabildiğini gösteren literatür ile uyumludur $4,7,29$.

Işlem öncesi, kontrol grubunun FLACC ağrı puanlarının, deney grubundan istatistiksel olarak anlamlı düzeyde yüksek olduğu saptanmıştır. Bu farklııık işlem yapılan odada dönencenin çalıştırılmadan bulundurulması nedeni ile deney grubundaki bebeklerin dikkatini çekerek ağrı puanlarını düşürmesinden kaynaklanmış olabilir. İşlem sırasında ve sonrasında, kontrol grubunun FLACC ağrı puanlarının, deney grubundan istatistiksel olarak anlamlı ölçüde yüksek olduğu saptanmıştır.

$\mathrm{Bu}$ bulgular sonucunda 3-6 aylık bebeklerde periferik intravenöz kateter uygulamasına bağlı gelişen ağrı algısının müzikli dönence kullanılarak azaltılabileceği belirlenmiştir. Literatürde çeşitli dikkati başka yöne çekme yöntemlerinin kullanıldığı araştırmalar mevcut olmakla birlikte, müzikli dönencenin kullanıldığı tek çalışma Özdemir ve Tüfekci'nin 25 2 aylık bebeklerde aşıya bağlı ağrıda müzikli dönencenin etkisini araştırdığı çalışmadır. Çalışmada deney grubunun işlem öncesi anksiyete, işlem sırası ve işlem sonrası ağrı puanlarının, kontrol grubuna göre istatistiksel olarak daha düşük olduğu belirlemiştir. Özdemir ve Tüfekci'nin ${ }^{25}$ sonuçları bulgularımızı destekler niteliktedir.

\section{SONUÇ ve ÖNERILER}

Bebeklerde ağrıya sebep olan periferik intravenöz kateterizasyon işlemlerinde, hemşireler tarafından müzikli dönencenin ağıı algısını azaltmak amacı ile kullanılabilir olduğu sonucuna ulaşılmıştır. Hemşireler tarafından sıklıkla uygulanan ve ağrıya sebep olan girişimlerin travmatik etkisini azaltmak atravmatik bakım felsefesinin bir gereğidir. Düşük maliyetle temin edilebilen, kolay kurulum ve kullanım kolaylığı olan müzikli dönence, ağrıya sebep olan diğer invaziv işlemlerde (intramüsküler enjeksiyon, üriner kateter uygulamaları gibi) dikkati başka yöne çekme aracı olarak kullanılması önerilir.

Etik Kurul Onayı: T.C. Maltepe Üniversitesi Etik Kurul'undan alınmıştır (Karar tarihi: 22/09/2017, Karar no: EKK/2017/82).

Çıkar Çatışması: Yoktur.

Finansal Destek: Bildirilmemiştir.

Katılımcı Onamı: Bakım vericilerinden bilgilendirilmiş onam alınmıştır.

Yazar katkıları:

Araştırma dizaynı: NA, SK, BE

Veri toplama: NA

Literatür araştırması: NA, SK, BE

Makale yazımı: NA, SK, BE

Teşekkür

Çalışmaya katılan tüm hastalarımıza teşekkür ederiz.

Ethics Committee Approval: Approval was obtained from the T.C. Maltepe University Ethics Committee (Decision date: 22/0972017, Decision number: EKK/2017/82).

Confict of Interest: Not reported.

Funding: None.

Exhibitor Consent: Informed consent was obtained from patients.

Author contributions:

Study design: NA, SK, BE

Data collection: NA

Literature search: NA, SK, BE

Drafting manuscript: NA, SK, BE

Acknowledgement: We would like to thank all patients who participated in the study.

\section{KAYNAKLAR}

1. Erdine S. Ağrı. 3. Baskı.İstanbul: Nobel Tıp Kitabevleri. 2007. p.7-9.

2. Oakes LL. Infant and child pain management. New York: Springer Publishing Company. 2011. Chapter 1; The problem of pain. $\mathrm{p}: 18-23$.

3. Twycross A, Dowden S, Stinson J. Managing pain in children. 2nd ed. United Kingdom: Blackweel Publishing Ltd; 2014. Chapter 1; Why Managing Pain in Children Matters. p:11. 
4. Törüner E, Büyükgönenç L. Çocuk sağlığı temel hemşirelik yaklaşımları. 1. Baskı. Ankara: Gökçe Ofset. 2012. Bölüm 5, Çocuklarda ağrı yönetimi; p:146-70.

5. Akcan E, Polat S. Yenidoğanlarda ağrı ve ağrı yönetiminde hemşirenin rolü. ACU Sağlık Bil Derg. 2017;(2):64-9.

6. Gupta HV, Gupta VV, Kaur A, Singla R, Chitkara, N, Bajaj $K V$ ve ark. Comparison between the analgesic effect of two techniques on the level of pain perception during venipuncture in children upto 7 years of age: A quasiexperimental study. Journal of Clinical and Diagnostic Research. 2014;8(8):1-4.

7. Conk Z. Pediatri hemşireliği. Ankara: Akademisyen Kitabevi; 2013. p:352-55.

8. Aslan FE. Ağrı doğası ve kontrolü. 2. Baskı. Ankara: Akademisyen Kitabevi. 2014. p. 25-8.

9. Özveren H. Ağrı kontrolünde farmakolojik olmayan yöntemler. Hacettepe Üniversitesi Sağlık Bilimleri Fakültesi Hemşirelik Dergisi. 2011;1:83-92.

10. Olmstead LD, Scott DS, Mayan M, Koop MS, Reid K. Influences shaping nurses use of distraction for children procedural pain. Journal for Specialist in Pediatric Nursing. 2014;162-71.

11. Kyle T, Carmen S. Essentials of pediatric nursing. 2nd ed. USA: Wolters Klumen Health; 2013. p:366-71.

12. Mutlu B, Balcl S. Effects of balloon inflation and coughtrick methods on easing pain in children during the drawing of venous blood samples: A randomized controlled trial. Journal for Specialists in Pediatric Nursing. 2015;20(3):178-86.

13. Sadeghi $T$, Mohammadi $N$, Shamshiri M, Bagherzadeh $R$, Hossinkhani N. Effect of distraction on children's pain during intravenous catheter insertion. Journal for Specialists in Pediatric Nursing. 2013;(18):109-14.

14. Tüfekci GF., Çelebioğlu A, Küçükoğlu S. Turkish children loved distraction: using kaleidoscope to reduce perceived pain. Journal of Clinical Nursing. 2009;18:2180-6.

15. Birnie KA, Noel M, Parker JA, Chambers CT, Uman LS, Kisely SR ve ark. Systematic review and meta-analysis of distraction and hypnosis for needle-related pain and distress in children and adolescents. Journal of Pediatric Psychology.2014;39(8):783-808.

16. Bahorski JS, Hauber RP, Hanks C, Johnson M, Ranner D, Stoutamire ve ark. Mitigating procedural pain during venipuncture in a pediatric population: $A$ randomized factorial study. International Journal of Nursing Studies. 2015;52(10):15553-64.

17. He H, Lee T, Jahja R, Sinnappan R, Julkunen KV, Pölkki T ve ark. The use of nonpharmacological methods for children's postoperative pain relief: Singapore nurses. Journal for Specialist in Pediatric Nursing. 2011;16:2738.

18. Göl i, Onarıcı M. Hemşirelerin çocuklarda ağrı ve ağrı kontrolüne ilişkin bilgi ve uygulamaları. Hacettepe Üniversitesi Hemşirelik Fakültesi Dergisi. 2015;20-9.

19. Merkel S, Voepel- Lewis T, Malviya S. Pain assessment in infants and young children: the FLACC scale. American Journal of Nursing. 2002;102(10):55-8.
20. Şenaylı Y, Özkan F, Şenaylı A, Bıçakçı Ü. Çocuklarda postoperatif ağrının FLACC ağrı skalasıyla değerlendirilmesi. Journal of Anesthesiology Reanimation. 2006;4(1):1-4.

21. Karakaya A, Gözen D. The effect of distraction on pain level felt by school-age children during venipuncture procedure and randomized controlled trial. Pain Management Nursing. 2016;17(1):47-53.

22. Tuna PT, Açıkgöz A. The effect of preintervention preparation on pain and pnxiety related to peripheral cannulation procedures in children. Pain Management Nursing. 2015;16(6):846-54.

23. Hasanpour M, Tootoonchi M, Aein F, Yadegarfar G. The effects of two non-pharmacologic pain management methods for intramuscular injection pain in children. Acute Pain. 2006;8(1):7-12.

24. Tüfekci FG, Erci B. Ağrıı işlemler sırasında ebeveynlerin bulunmasının ve bazı faktörlerin çocukların ağrı toleransına etkisi. Atatürk Üniversitesi Hemşirelik Yüksekokulu Dergisi. 2007;10(2).

25. Özdemir KF, Tüfekci GF. The effect of using musical mobiles on reducing pain in infants during vaccination. Journal of Research in MedicalSciences. 2012;17(7):662-67.

26. Sikorova L, Hrazdilova P. The effect of psychological intervention on perceived pain in children undergoing venipuncture. Biomedical Papers of the Medical Faculty of the University Palacky Olomouc Czech Republic.2011;155(2):149-54.

27. Bisogni S, Dini C, Olivini N, Ciofi D, Giusti F, Caprilli S ve ark. Perception of venipuncture pain in children suffering from chronic diseases. BMC Research Notes. 2014;18(7):735.

28. Başbakkal Z, Sönmez S, Celasin NŞ, Esenay F. 3-6 yaş grubu çocuğun akut bir hastalık nedeniyle hastaneye yatışa karşı davranışsal tepkilerinin belirlenmesi. Uluslararası İnsan Bilimleri Dergisi. 2010;7(1).

29. Üstün G, Erşan EE, Kelleci M, Turgut H. Hastanede yatan çocuklarda psikososyal semptomların bazı değişkenler açısından incelenmesi. Cumhuriyet Tıp Dergisi. 2014;36:25-33. 